\title{
A transit-time flow meter for measuring milliliter per minute liquid flow
}

\author{
Yang, Canqian; Kymmel, Mogens; Søeberg, Henrik
}

Published in:

Review of Scientific Instruments

Link to article, DOI:

$10.1063 / 1.1140247$

Publication date:

1988

Document Version

Publisher's PDF, also known as Version of record

Link back to DTU Orbit

Citation (APA):

Yang, C., Kymmel, M., \& Søeberg, H. (1988). A transit-time flow meter for measuring milliliter per minute liquid flow. Review of Scientific Instruments, 59(2), 314-317. https://doi.org/10.1063/1.1140247

\section{General rights}

Copyright and moral rights for the publications made accessible in the public portal are retained by the authors and/or other copyright owners and it is a condition of accessing publications that users recognise and abide by the legal requirements associated with these rights.

- Users may download and print one copy of any publication from the public portal for the purpose of private study or research.

- You may not further distribute the material or use it for any profit-making activity or commercial gain

- You may freely distribute the URL identifying the publication in the public portal

If you believe that this document breaches copyright please contact us providing details, and we will remove access to the work immediately and investigate your claim 


\title{
A transit-time flow meter for measuring milliter per minute liquid flow
}

\author{
Canqian Yang, a) M. Kümmel, and $H$. Sojeberg \\ Department of Chemical Engineering, Technical University of Denmark, DK-2800 Lyngby, Denmark
}

(Received 6 July 1987; accepted for publication 30 September 1987)

\begin{abstract}
A transit-time flow meter, using periodic temperature fiuctuations as tracers, has been developed for measuring liquid flow as small as $0.1 \mathrm{ml} / \mathrm{min}$ in microchannels. By injecting square waves of heat into the liquid flow upstream with a tiny resistance wire heater, periodic temperature fiuctuations are generated downstream. The fundamental frequency phase shift of the temperature signal with respect to the square wave is found to be a linear function of the reciprocai mean velocity of the fluid. The transit-time principle enables the flow meter to have high accuracy, better than $0.2 \%$, and good linearity. This flow meter will be used to measure and control the small liquid flow in microchannels in flow injection analysis.
\end{abstract}

\section{INTRODUCTION}

Small hiquid flow measurement is of importance for the development of microchemical analysis and many other techniques, but it is still one of the most difficult areas among measurement techniques.

In our previous work, ${ }^{1}$ the self-heated thermistor flow meter based on micro NTC glass-encapsulated thermistor probes was developed, capable of measuring liquid flow as small as tenths of a milliliter per minute with fast dynamic response. However, the thermistor flow meter can only offer medium accuracy, because it is impossible to completely eliminate the ambient temperature dependence of the output characteristic.

Unlike the thermistor flow meter, the transit time flow meter does not suffer from the influence of the ambient temperature since it is based on the principle of determining the mean velocity of the fluid through the transit time of the tracer. Since, generally speaking, time can be measured accurately, the transit-time fiow meter has the potential possibility to measure small liquid fow with high accuracy and good linearity. In addition, the calibration of the transit-time flow meter is almost independent of the type of fluid to be measured.

Artificial fluctuation in temperature is often used as a tracer in transit-time flow meters for liquid flow measurement, because temperature fuctuation is easier to generate, and it has an advantage of not disturbing the chemical analysis if the amplitude of the temperature fuctuation is limited to a few degrees.

Some successful results on the transit-time flow meters using fluctuation in temperature as a tracer for measuring liquid flow have been reported. A flow meter using heat pulses as tracers and detecting the arrival time of the heat pulses downstream was capable of measuring small liquid flow in HPLC techniques. ${ }^{2,3}$ Another method, using a pseudonoise pulse sequence of heat as a tracer and estimating the transit time by cross correlation, was used to measure medium liquid flow $w^{4,5}$ with the main advantage that the required magnitude of the temperature fuctuations can be reduced, which is quite suitable to some applications. Using square waves of heat as tracers ${ }^{5,6}$ and determining the shift of the waveform of the periodic temperature signal with respect to the square waves was reported for measuring water flow, but with a much higher flow rate than applied here.

The transit-time flow meter described below, based on injecting square waves of heat as tracers and determining the flow rate by the fundamental frequency phase shift of the periodic fuctuations in temperature, is capable of measuring liquid fow as small as $0.1 \mathrm{ml} / \mathrm{min}$. The fundamental frequency phase-shift method eliminates the influence of the harmonics on determining the transit time and ensures the linear relationship between the phase shift and the reciprocal flow rate so that the fow meter has an accuracy better than $0.2 \%$ (at normal ambient laboratory temperatures) and 0.9999 correlation coefficients, indicative of high linearity.

\section{THE PRINCIPLE AND THE IMPLEMENTATION OF THE FEOW METER}

Figure 1 shows the principle of the transit-time flow meter. In a cross section of the flow channel, a tiny heater is mounted, which is supplied with a square-wave voltage at an appropriate frequency. The heater generates square waves of heat which are transferred by the axial thermal transport in the channel, causing temperature fuctuation downstream. At two cross sections downstream, iwo temperature sensors are mounted and used to detect the periodic temperature signals.

In steady state, the temperature fluctuation becomes periodic so that the fundamental frequency phase shift with respect to the square wave of the temperature signal, or the

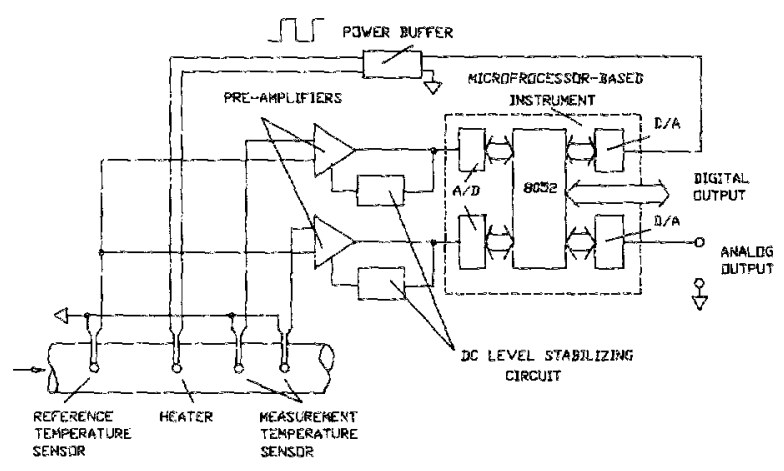

Fig. 1. The block diagram of the transit-time flow meter. 
fundamental frequency phase difference between the two temperature signals detected downstream, will be inversely proportional to the mean velocity of the fiuid.

A microprocessor-based instrument with an interface of multichannel $A / D$ and $D / A$ converters is designed for the computation of the phase shift or the phase difference by means of a frequency analysis program, and thus the flow rate is determined. The microprocessor-based instrument also generates a square-wave voltage with a duty cycle of $50 \%$, which is amplified to sufficient power before it is fed to the heater.

The variation of the fluid temperature causes a change in the dc component of the temperature signal, the magnitude of which may be much greater than the amplitude of the pulsation component, often forcing the $\mathrm{A} / \mathrm{D}$ converters out of the input range. The reference temperature sensor mounted upstream is used to compensate for the infuence of the fluid temperature.

The dc component of the square-wave electric heating generates another part of the de component in the temperature signal, which depends on the flow rate. The dc level stabilizing circuit is designed with the purpose of removing the change in the de component due to this effect, maintaining the de level in the center of the input range of the $A / D$ converter.

Figure 2 shows the flow cell. The diameter of the flow cell is only $1.3 \mathrm{~mm}$. The first temperature sensor is $18 \mathrm{~mm}$ away from the heater and the two measurement temperature sensors are spaced $8 \mathrm{~mm}$ apart. The flow cell is machined from a material with good thermal isolation and resistance to chemical corrosion. The heater coil, made of coated resistance wire with $0 . d$. of $0.1 \mathrm{~mm}$ and high specific resistance of $171 \Omega / \mathrm{m}$, has a size of only $0.8 \mathrm{~mm}$ in $0 . d$ and $0.8 \mathrm{~mm}$ in length. The resistance of the heater is about $9 \Omega$, so it generates about $200 \mathrm{~mW}$ of heat at a current of $150 \mathrm{~mA}$.

Some time is required for the temperature of the flow cell to reach the steady state after the flow meter starts. The "warm-up" time is related to the heat capacity of the flow cell wall. A small body of the flow cell will be advantageous to reduce the "warm-up" time. The external diameter of the flow cell is selected to $5 \mathrm{~mm}$.

Micro NTC glass-encapsulated thermistor probes with a size of $0.5 \mathrm{~mm}$ in o.d. (Fenwal Electronics ${ }^{7}$ ) are used as temperature sensors. In order to obtain good compensation for the change of the dc component due to the variation of the fluid temperature, the therrnistors must have relatively matched characteristics. They all work in zero-power condition.

Figure 3 shows the electronic configuration of the ampiffer and the dc level stabilizing circuit for the temperature

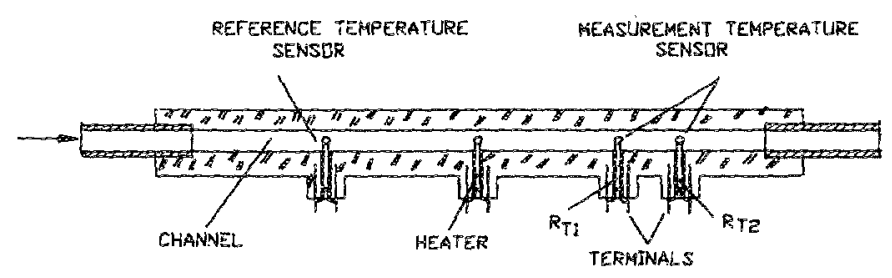

FIG. 2. The flow cell of the transit-time fow meter.

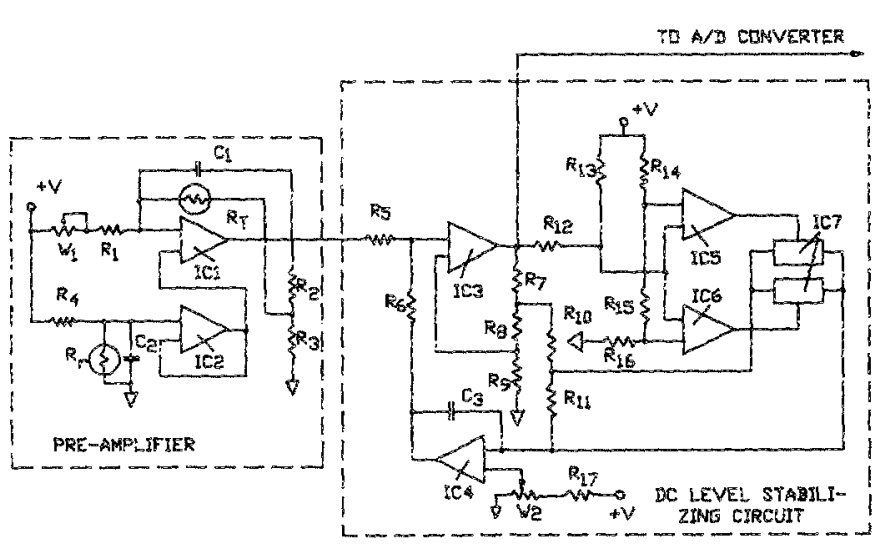

Frg. 3. The electronic cireuit of the temperature transducers of the transittime flow meter $\left(R_{r}\right.$ : the measurement thermistor and $R_{r}$ : the reference thermistor).

transducers. The overall gain for the temperature signal is about $7 \mathrm{~V} /{ }^{\circ} \mathrm{C}$ if the thermistors have temperature coefficients of $3.5 \% /{ }^{\circ} \mathrm{C}$. The de level stabilizing circuit is essentially a high-pass filter, the rime constant of which is selected in such a way that compensation is as fast as possible without observable attenuation in the amplitude or additional phase shift at the fundamental frequency. The dc level is maintained constant but is adjustable through the potentiometer in the circuit. In addition, comparators and analog switches are combined to shorten the time constants when the output is out of the range of $0-5 \mathrm{~V}$.

The fundamental frequency phase shift of the temperature signal with respect to the square waves is based on Fourier analysis (refer to, for example, Ref. 9 ) by using approximate integration:

$$
\begin{aligned}
& \varphi=(180 / \pi) \arctan \left(b_{1} / a_{1}\right) \quad(\mathrm{deg}), \\
& a_{1}=\frac{2}{N} \sum_{n=0}^{N-1} T\left(n T_{s}\right) \sin \left(\frac{2 \pi n}{N}\right), \\
& b_{1}=\frac{2}{N} \sum_{n=0}^{N-1} T\left(n T_{s}\right) \cos \left(\frac{2 \pi n}{N}\right),
\end{aligned}
$$

where $N$ is the sampling number in a period, $T_{s}^{r}$ is the sampling interval, which is selected as $0.5 \mathrm{~s}$, and $T\left(n T_{s}\right)$ is the temperature signal at $t=n T_{s}$.

Introducing the signs of $a_{1}$ and $b_{1}$, Eq. (1) can be modified to express the phase shift in four quadrants as follows:

$$
\begin{aligned}
\varphi= & -\operatorname{sgn}\left(b_{1}\right)\left(\operatorname { s g n } ( a _ { 1 } ) \left\{\arctan \left[\operatorname{abs}\left(b_{1} / a_{1}\right)\right]\right.\right. \\
& \times(180 / \pi)-90\}-90)+180(\operatorname{deg}),
\end{aligned}
$$

and this is the algorithm used for the signal processing of the microprocessor-based instrument (see Fig. 4).

\section{RESULTS AND DISCUSSION}

The experimental results of the fundamental frequency phase shift with respect to the square wave as linear functions of reciprocal volumetric flow rate are shown in Fig. 5. Linear regression anaiysis results in linear correlation coefficients of 0.99980 to 0.99995 , indicating their exceilent linearity.

The key for the phase-shift lines to achieve good linearity is the fundamental frequency phase-shift method. Since 


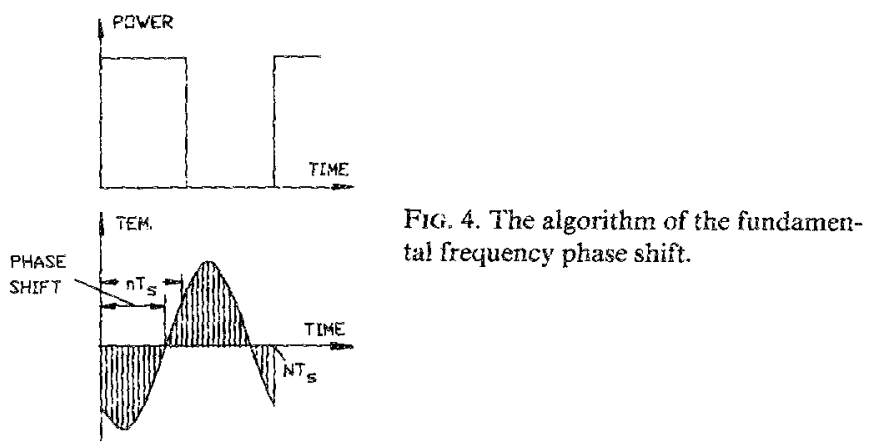

the heating power is of square wave, the temperature signals contain harmonies, although in certain frequency ranges the temperature signal is quite sinusoidal and relatively free of harmonics. But at high flow rates and low square-wave frequencies, the waveform deviates much from the sine wave, and the harmonics result in considerable nonlinearity if the fundamental frequency phase-shift method is not used.

The transit-time lines are shown in Fig. 6 , where the transit time is defined as $A / 360 F$ ( $A$ : the phase shift in degrees, $F$ : the operating frequency).

Under the idealized assumptions of the plug velocity profile and plug temperature profile in the channel, ${ }^{8}$ the phase-shift characteristic of the transit-time fiow meter can be regarded as a transportation lag with a phase shift of $2 \pi F L / V_{0}$ in radians, where $V_{0}$ is the mean velocity of the fluid and $L$ is the distance of the temperature sensor from the heater. Therefore, the slope of the transit-time line will be independent of the operating frequency in the idealized models, as also shown in Fig. 6.

However, the slopes of the transi-time lines are not independent of the operating frequency in the actual transittime flow meter. The slopes of the actual transit time are always larger than, but approach the idealized slope as the operating frequency increases. The dependence of the slopes of the transit-time lines on the operating frequency can be explained from the frequency dependence of the penetration thickness of the ac component of the heat fux through the flow cell wall. For a perfect isolation of the flow cell wall, the slopes of the transit-time line will be equal to the idealized model.

The phase-shift lines in Fig. 5, hence the transit-time

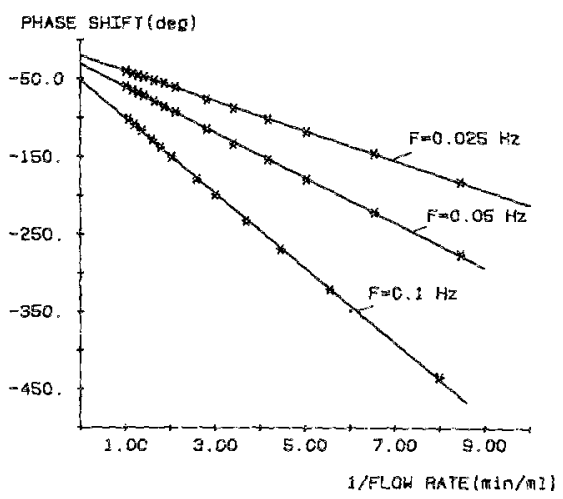

Fig. 5. The fundamental frequency phase shift as a function of the reciprocal fow rate at different frequencies.

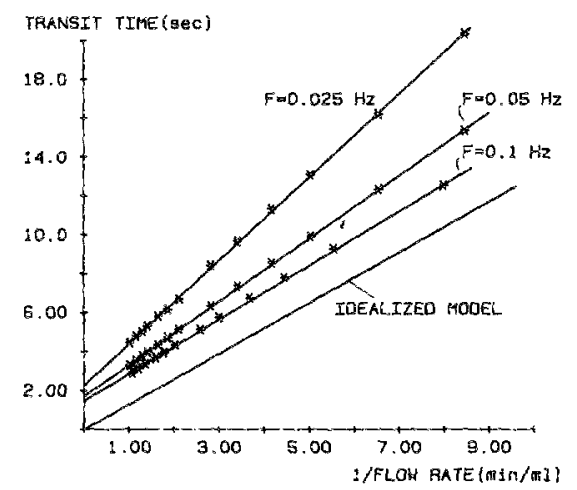

FIG. 6. The transit time as a function of the reciprocal volumetric fiow rate at different frequencies.

Iines in Fig. 6, do not pass through the origin, and the intercepts on the vertical axis depend on the operating frequency. Thermal dynamic analysis shows that the intercepts on the phase axis are caused mainly by the time constants of the heater and the measurement temperature sensor, and the sampling time of the $A / D$ converters. The resistance of the lead wires of the heater would also cause some phase shift if the resistance cannot be neglected.

However, it has been found that the two phase-shift lines, detected at the two temperature sensors, respectively, cross the vertical axis at the same point. Furthermore, the ratio of slopes of these two transit-time lines is equal to the ratio of the distances of temperature sensors from the heater. This indicates that the zone between the heater and temperature sensor has no contribution on the intercept. Therefore, the transit time between the two temperature sensors would be straight lines through the origin, as shown in Fig. 7. This feature is quite convenient to the calibration of the flow meter if the phase difference is used to determine the flow rate.

The variation of the amplitude of the temperature signal is also important to the signal processing and the selection of the magnitude of the heating power. Figure 8 shows the fundamental frequency amplitude of the temperature signal as a function of the flow rate and the operating frequency. At very small flow rate, almost no visible temperature signal can be detected downstream because the temperature fluctuations in the fluid have been damped due to thermal dispersion before the fluid arrives at the temperature sensors in this

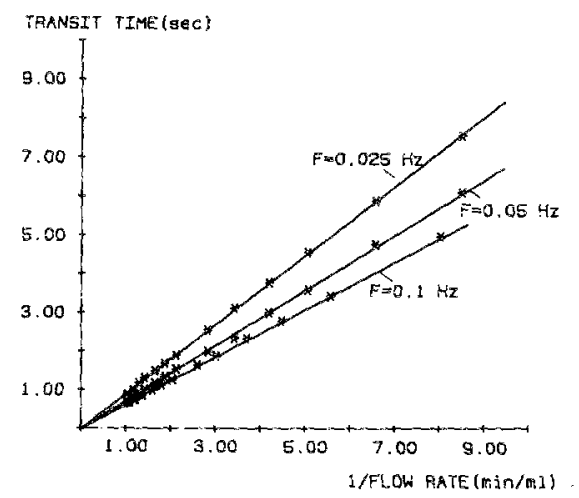

Fig. 7. The iransit-time lines between two detected points are straight lines through the origin. 


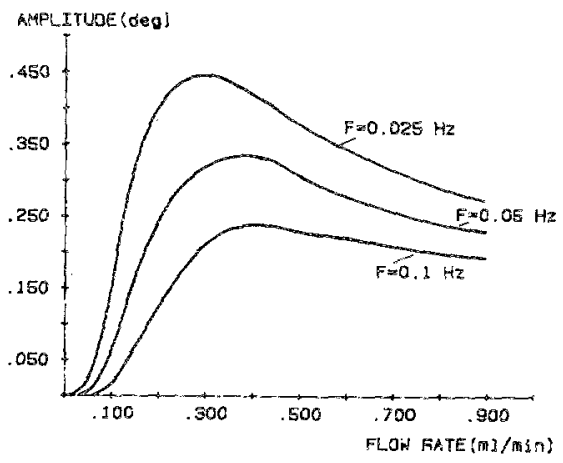

Fig. 8. The fundamental frequency amplitude of the temperature signal at different frequencies (detected by the measurement sensor $R_{T_{1}}$ ).

case. With the increasing flow rate, more heat is brought downstream by the axial thermal transport. The ampitude increases rapidly with the increasing flow rate and, at some flow rate, the amplitude reaches a maximum. As the flow rate increases further, almost all of the heat generated by the heater has been transferred downstream, and the amplitude of the temperature signal is inversely proportional to the mass flow rate according to the heat energy balance if the heat loss through the flow cell wall can be neglected.

That the amplitude of the temperature signal decreases with the increasing operating frequency in Fig. 8 can also be explained from the frequency dependence of the penetration thickness of the ac component of the heat flux through the flow cell wall.

Since the phase shift of the transit-time fiow meter has good linearity, the calibration is quite simple. Through the measurement of the phase shift at a few points and by determining the slope and the intercept at an appropriate operating frequency, a calibration with sufficient accuracy will be obtained.

Transit-time flow meters are not capable of measuring flow ranging from zero. At very small flow rate, the amplitude of the temperature signal is too small to process accurately and, hence, results in large measurement errors.

The amplitudie of the temperature signal decreases with the increasing flow rate, but it is no problem to the applications of the flow meter since the amplitude decreases slowly.

An appropriate square-wave frequency must be selected according to the possible range of the flow rates. Too high a frequency would cause a phase shift or phase difference larg-

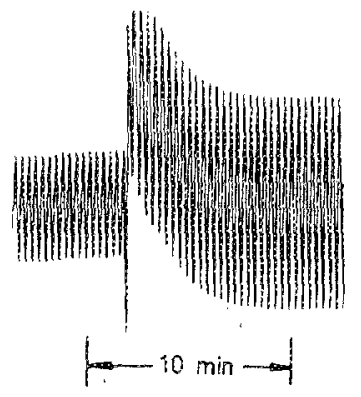

(o)

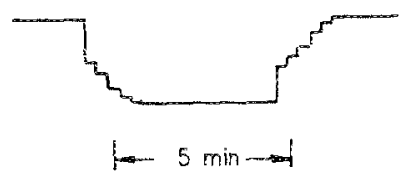

(b)
FIG. 9. The temperature signal (a) and the dynamic response (b) when the flow rate suddenly changes from 0.12 to $0.15 \mathrm{ml} / \mathrm{min}$ (measured by $R_{T 1}$ at frequency $0.05 \mathrm{Mz}$ ). er than $360^{\circ}$. At too low a frequency, the phase shift or the phase difference is small, which cannot be measured accurately. Furthermore, the drift due to the ambient temperature change and the thermal turbulence will reduce the stability.

As mentioned above, the transit-time principle enables the fow meter to have high accuracy since time can be measured accurately. In 270 consecutive periods in experiments, a standard deviation less than $0.1 \%$ of its mean value is given when the flow rate is maintained constant at $0.15 \mathrm{ml} / \mathrm{min}$. In a several month testing period with deionized water as the fluid, the flow meter demonstrated excellent stability. The drift within $48 \mathrm{~h}$ is about $0.2 \%$ at a full scale of $0.25 \mathrm{ml} / \mathrm{min}$. Normal change in ambient temperature $\left( \pm 5^{\circ} \mathrm{C}\right)$ has no observable effect on the accuracy.

The measurement results are not sensitive to the amplitude of the square-wave voltage applied to the heater. The indication changes less than $0.1 \%$ as the amplitude of the square wave reduces by $15 \%$.

Figure 9 (a) shows the temperature signal when the fow rate suddenly changes from 0.12 to $0.15 \mathrm{ml} / \mathrm{min}$. It also shows that the dic level stabilizing circuit works efficientiy. Figure $9(b)$ shows the analog output record. It observes an approximately exponential law. The dynamic response time is about $2 \mathrm{~min}$ in this example.

Compared to the thermistor flow meter for measuring small liquid flow, the transit-time flow meter has much higher accuracy and much better linearity and stability, and this is its main advantage. But the dynamic response of the transit-time flow meter is much slower than that of the thermistor flow meter, and this is the main disadvantage of the transit-kime flow meter.

The idea of combining the advantage of fast dynamic response of the thermistor flow meter and the advantage of high accuracy and good linearity and stability of the transittime flow meter is an attractive research topic.

The work to establish the thermal dynamic model of the transit-time flow meter for the purpose of optimizing the design of the flow cell is on its way. It would be possible to measure even smaller liquid fow by the use of transit-time flow meters.

\section{ACKNOWLEDGMENT}

The authors are grateful to the FTU project (The Danish Research Council ) Mikrokemiske Målemetoder, Grant No. 5.17.2.6.03, for the financial support of equipment.

a) On leave from Shanghai Research Institute of Chemical Industry, The People's Republic of China.

'C. Yang, M. Kümmel, and H. Soeberg, Sensors Actuators to be published).

${ }^{2}$ T. E. Miller and H. Small, Anal. Chem. 54, 907 (1982).

${ }^{3}$ G. A. Hoffman and T. E. Miller, Anal. Chem. 56, 1682 (1984).

${ }^{4}$ W. Witte and P. W. Baier, Acta IMEKO, 159 (1982).

${ }^{5} \mathrm{R} . \mathrm{K}$. Prasad, University of Wales Swansea, Ph.D. thesis, 1982

'R. Goria, G. Martini, A. Rivetti, and S. Lorefice, Sensors Actuators 6, 215 (1984).

7Thermistor Manual (Fenwal Electronics, MA, 1983).

${ }^{8}$ R. Bird, W. E. Stewart, and E. N. Lightfoot, Transport Phenomena (Wiley, New York, 1960).

'G. A. Korn and T. M. Korn, Mathematical Handbook for Scientists and Engineers (McGraw-Hill, New York, 1961), p. 134. 